Supplemental Information

\title{
Bioinorganic Interface: Mechanistic Studies of Protein-Directed Nanomaterial Synthesis
}

Kristina L. Roth, Xi Geng, Tijana Z. Grove*

\section{AUTHOR ADDRESS}

Department of Chemistry, Virginia Polytechnic Institute and State University, Blacksburg, Virginia 24061, United States

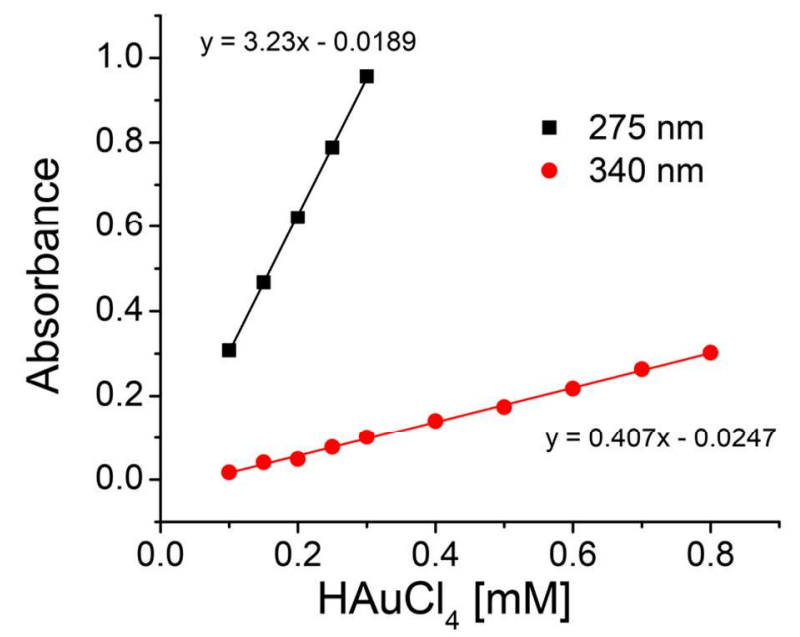

Figure S1. Beer-Lambert plots for $\mathrm{HAuCl}_{4}$ at 275 and $340 \mathrm{~nm}$. 


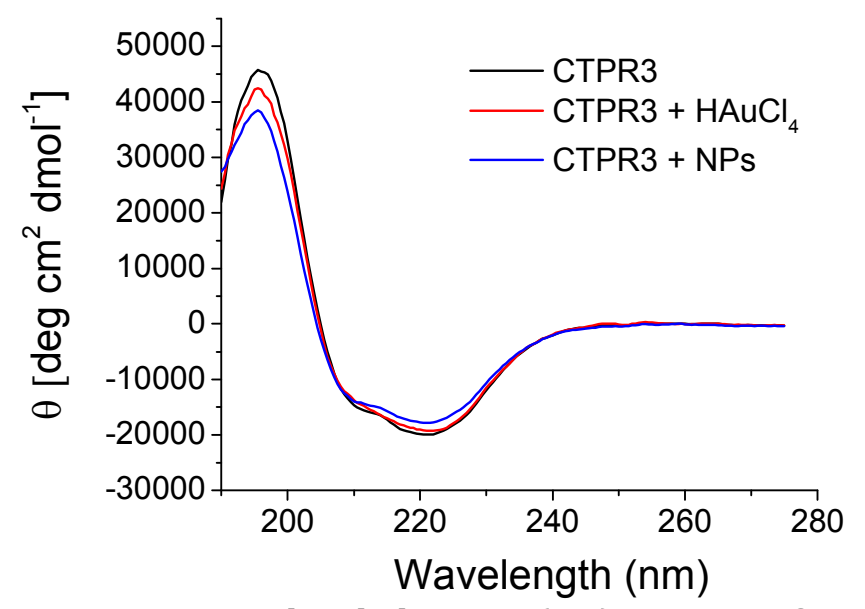

Figure S2. Circular dichroism (CD) spectra of CTPR3 (black), CTPR3 after titration with $\mathrm{HAuCl}_{4}$ (red), and CTPR3 after formation of NPs (blue).

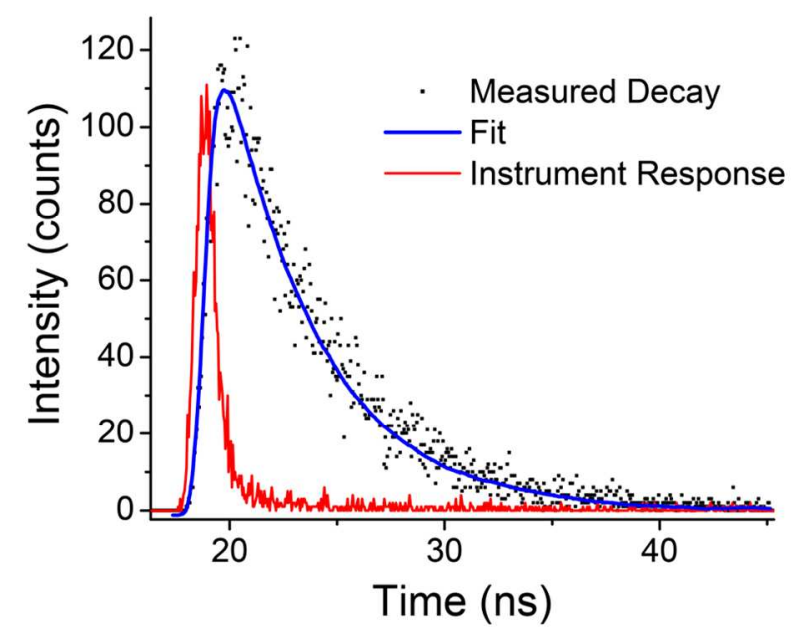

Figure S3. Time resolved fluorescence of CTPR3. 


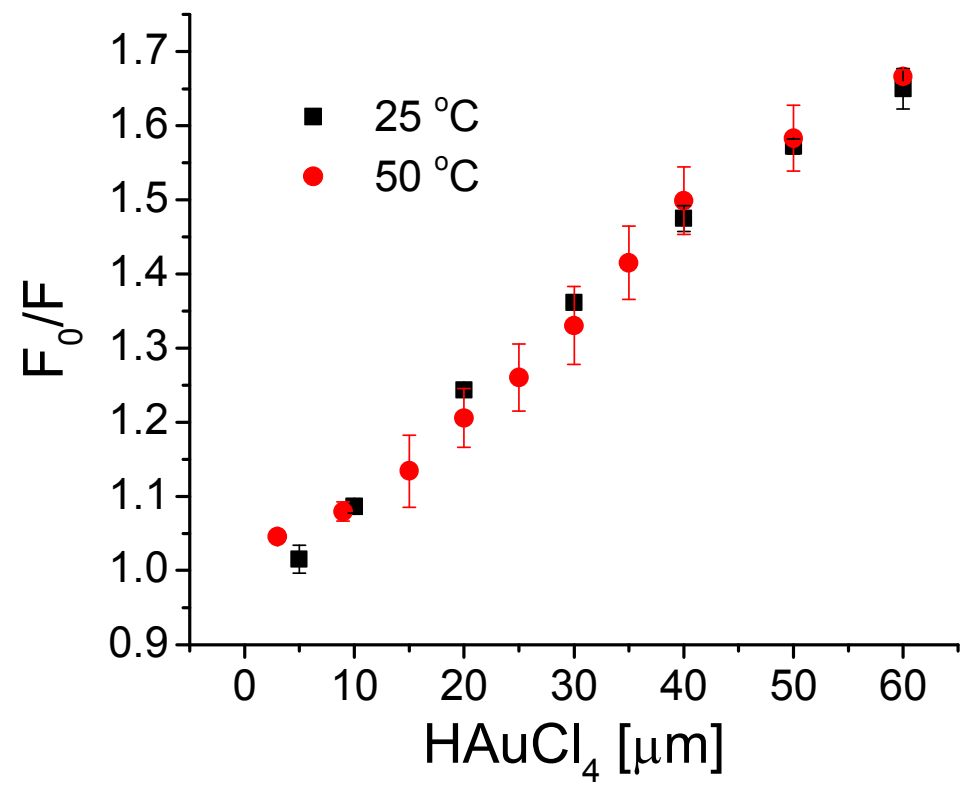

Figure S4. Fluorescence quenching of CTPR3 by $\mathrm{HAuCl}_{4}$ at $25^{\circ} \mathrm{C}$ and $50^{\circ} \mathrm{C}$.

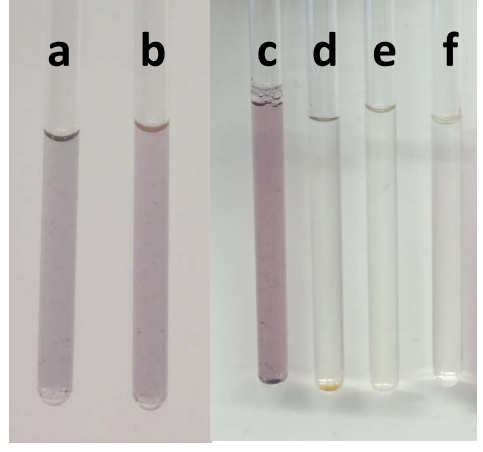

Figure S5. Images of NMR tubes after 3 weeks with $\mathrm{HAuCl}_{4}$ in $5 \mathrm{mM} \mathrm{Na}_{2} \mathrm{HPO}_{4}(\mathrm{a} \& \mathrm{~d})$, $5 \mathrm{mM} \mathrm{Na}_{2} \mathrm{HPO}_{4}$ and $230 \mathrm{mM} \mathrm{NaCl}$ (b \& e), and $5 \mathrm{mM} \mathrm{Na}_{2} \mathrm{HPO}_{4}$ and $230 \mathrm{mM} \mathrm{NaNO}_{3}$ (c \& f). Samples a, b, and c also have CTPR3 in a 13:1 $\mathrm{HAuCl}_{4}$ to CTPR3 ratio. 


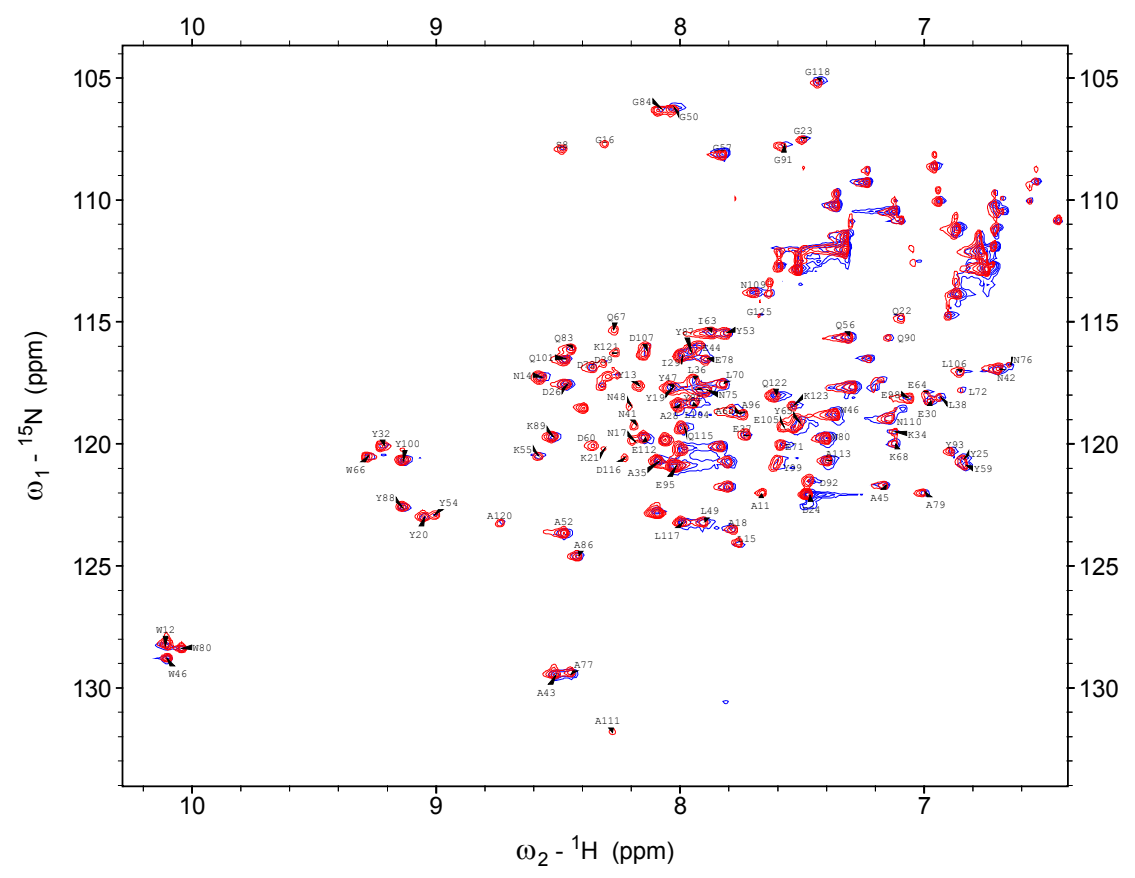

Figure S6. Overlay of ${ }^{1} \mathrm{H}^{-15} \mathrm{~N}$ HSQC spectra of CTPR3(red) and CTPR3 sample after NP formation (blue).

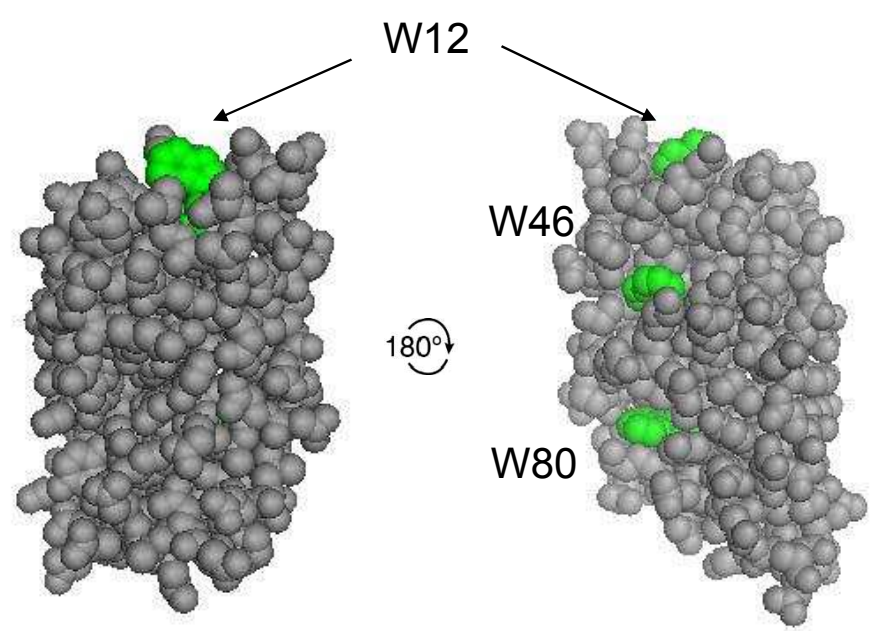

Figure S7. A space-filling model of CTPR3 with tryptophan residues in green. 